\title{
Assessment of a Communication Assistive Technology for Individuals with Deafblindness: A Case Study
}

\author{
Sylvie Cantin, Walter de Abreu Cybis, Suzanne Trudeau, Frédérique \\ Poncet, Walter Wittich , Marie-Chantal Wanet-Defalque
}

\section{Acknowledgements}

The authors warmly thank Francine Baril, documentation technician at INLB, the exceptional person with deafblindness who participated in the study, as well as the highly collaborative staff of the restaurant Vincent in Montreal. 


\begin{abstract}
The main goal of this study was to evaluate a communication assistance device (CAD) for individuals with deafblindness, based on a braille display notetaker connected via Bluetooth to an iPhone. This study examined the use of this device by a 61-year-old woman living with Usher syndrome with sighted and hearing interlocutors during three restaurant outings.

The study had three specific objectives: 1) To evaluate the participant's and her interlocutors' perceptions of their productivity in the communication interaction in real-life situations, without and with the CAD; 2) To evaluate the participant's emotional experience after using the CAD; and 3) To describe how the communication interactions between the participant and her interlocutors work, without and with the CAD. The relevance, utility and interest of such a communication support technology became clearly apparent, along with the enthusiasm it aroused in her interlocutors. Despite the empowerment it provided, the huge differences in some aspects of interactions made without and with the CAD suggest that the constraints introduced by the use of a CAD modify the nature of communication. Four recommendations are made. Any future development of the technology intended for users with minimal experience working with computers and electronic devices should be encouraged.
\end{abstract}

\title{
Keywords
}

Deafblindness; Dual sensory loss; Assistive communication technology; iPhone; Braille notetaker; Assessment; Usability; Effectiveness; Living laboratory 


\section{Introduction}

The Nordic Definition defines deafblindness (DB) as "a combined vision and hearing impairment of such severity that it is hard for the impaired senses to compensate for each other" (Nordic Centre for Welfare and Social Issues, 2016, p. [2]). The disabilities associated with DB exceed the simple sum of those confronting individuals living with only one sensory impairment (Dammeyer, 2015; Schneider et al., 2011). Thus, the impact of both impairments is intensified, due to the impossibility of effective compensation for sensory loss. Such combined vision and hearing loss often impedes language and communication (Dammeyer, 2014), reduces opportunities to interact and communicate with others (Prain, McVilly, Ramcharan, Currie, \& Reece, 2010), affects social life, access to information, orientation and mobility (Nordic Centre for Welfare and Social Issues, 2016) and impacts on general functioning (Heine \& Browning, 2015), especially communication.

Assistive Products for Communication and Information, as classified by ISO 9999:2016 (International Organization for Standardization, 2016), refer to "Devices for helping a person to receive, send, produce and process information in different forms" (Mordini et al., 2018, p. 15). McDonnall, Crudden, LeJeune, Steverson, and O'Donnell (2016) have shown that communication assistive devices (CADs) help foster communication and reduce the isolation experienced by people with DB. According to Perfect, Jaiswal, and Davies (2018), assistive technologies to access the internet can also reduce the impact of DB on communication, interpersonal interactions and relationships, and community, social and civic life. As the tactile sense is important to help compensate for the combined vision and hearing impairment (Nordic Centre for Welfare and Social Issues, 2016), braille devices are of great importance. They include devices for (i) distant communication, like telephone devices for the deaf (TDD or TTY) (Mordini et al., 2018), the Helen Keller Phone system for communication via Skype (Ohtsuka, Hasegawa, Sasaki, \& Harakawa, 2012) and braille communicators (combination of a braille notetaker and a braille phone) (Mordini et al., 2018) and (ii) person-to-person communication, as the Screen Braille Communicator for persons with DB with sighted persons (Mordini et al., 2018) and the SmartFingerBraille for face-toface and distant communication between persons with DB (Ozioko, Taube, Hersh, \& Dahiya, 2017).

Despite assistive technology and communication services being common research and rehabilitation priorities as regards people with deafblindness (Wittich, Jarry, Groulx, Southall, \& Gagne, 2016), among the assistive devices being developed, few seem to be tested for effectiveness with this population. A systematic review on assistive technology aimed at enabling internet access for individuals with deafblindness revealed that "no studies appear to exist that specifically evaluate the effectiveness of [this] assistive technology" (Perfect et 
al., 2018, p. 5). Moreover, usability of devices is rarely discussed or analyzed (Perfect et al., 2018; Wittich, Southall, \& Johnson, 2016).

Given the development of new communication assistance technologies (not to mention the multiplicity of exploitable internet services and smartphone applications) and the fact that several authors have encouraged the development of communication assistive technologies as a research priority (LeJeune, 2010; Saunders \& Echt, 2007; Wittich, Jarry, et al., 2016), the time has come to measure their effects in order to accurately assess their value and scope, in terms of effectiveness, for persons with DB.

The purpose of this article is to report on the experience of a person with deafblindness using a braille CAD in an everyday community activity, i.e. restaurant outings, adopting the "living laboratory" approach. More specifically, the objectives pursued were: 1) To evaluate the participant's and her sighted and hearing interlocutors' perceptions of their productivity in the communication interaction in real-life situations, without and with the CAD; 2) To evaluate the participant's emotional experience after using the CAD; and 3) To describe how the communication interactions between the participant and her sighted and hearing interlocutors work, without and with the CAD.

\section{Method}

\section{Ethics Approval}

This study was approved by the Research Ethics Committee of the Center for Interdisciplinary Research in Rehabilitation of Greater Montreal (CRIR-0854-0613).

\section{Study Design}

To meet the study's objectives, a single case study design was employed. The participant was placed in a real-life situation of restaurant outings with an attendant. An A-B-C study design was used: in phase $\mathrm{A}$, the attendant and the participant interacted in tactile sign language; during phase $\mathrm{B}$, the attendant and the participant interacted using the CAD (a single interlocutor); and in phase $\mathrm{C}$, the attendant and a waitress interacted with the participant using the CAD ( 2 interlocutors). A waitress employed by the restaurant was present in each of the three phases. Her role was to welcome the participant and her attendant and to interact with them as part of their meal. In phase $C$, the waitress was asked to interact directly with the participant using the CAD.

\section{Methodological Approach}

The methodology used was inspired by the general user-centered design approach proposed by the ISO 9241-210:2010 (International Organization for Standardization, 2010). The user-centered contextual analysis and evaluation steps proposed by this approach were 
employed. Three concepts were used in this study: perceived productivity in communication interaction, emotional experience and communication interaction functioning.

The concept of perceived productivity in communication interaction was inspired by the usability concept, defined by the ISO 9241-11:2018 standard as "the extent to which a system, product or service can be used by specified users to achieve specified goals with effectiveness, efficiency and satisfaction in a specified context of use" (International Organization for Standardization, 2018). Usability applies to the user's immediate interaction with a technological device and can be measured objectively. To provide a measurement better suited to the needs of this study, two derivations of the concept of usability were developed: 1) perceived productivity has been limited to measures of users' perceptions, with and without deafblindness, of effectiveness and efficiency in their communication interactions, with the perception of satisfaction linked to the emotional experience, and 2) the notion of perceived productivity has been extended to human communication interactions without the aid of a CAD (phase A), i.e. by means of tactile sign language. This construct therefore made it possible to compare communication interactions between the three phases.

The concept of emotional experience was based on the more general concept of "user experience" as defined by the ISO 9241-11:2018: the set of "user's perceptions and responses that result from the use and/or anticipated use of a system, product or service" (International Organization for Standardization, 2018). Conceptually, the user experience is subjective, and varies as the user is exposed to or uses a product (Hassenzahl, 2004). According to Hassenzahl (2004), the consequences of interactions with a product are apparent in the user's perceptions as well as in his or her behavioural and emotional responses. In this study, the emotional experience construct referred to a set of emotional perceptions and responses from the participant as a result of actual use of the CAD.

The concept of communication interaction functioning referred to the communication dynamic between partners. It is based on the interaction model proposed by Van Den Tillaart (2011), which breaks down the communication interaction into three phases: (1) opening, (2) maintaining and (3) closing contact. Two additional concepts have been incorporated into this model: speech turn management (management of the alternation of speaker/hearer roles by the two interlocutors) and feedback (information obtained from the interlocutor leading to the modification of one's next statement). These were proposed by Iché, Rives, and Joyeux (2012) in their tool Protocole Toulousain d'Évaluation de la Communication du Couple Aphasique (PTECCA / the Toulouse protocol for assessing communication in aphasic couples) and match the conversational analysis approach developed by Kerbrat-Orecchioni (1986).

Perceived productivity (Objective 1) and the emotional experience (Objective 2) were evaluated through semi-structured interviews. The communication interaction function between the participant and her interlocutors (Objective 3) was evaluated using a field observation grid and a grid for the video material recorded during the interactions. 


\section{Participant}

The study participant was a French-speaking client in the joint deafblindness rehabilitation program at the Institut Nazareth et Louis-Braille (INLB) and the Institut Raymond-Dewar (IRD), two of the rehabilitation centres in the Montreal region responsible for vision and hearing impairment, respectively. The participant turned 61 years old during the course of the study. She had a diagnosis of type 1 Usher syndrome: deaf from birth, she lost her sight in her right eye at the age of 25 and in her left eye, though already reduced, at the age of 40 . She was previously married, had no children and lives alone. She had a Deaf friend who accompanies her when she goes shopping and to doctor and dentist appointments. She communicates using tactile sign language and travels with the assistance of a guide dog. The participant holds a high school diploma and two study certificates: Commercial Assistant and Perforator Operator \& Typist. She has a superior knowledge of written French and French braille, and has used braille technologies since the age of 43 . She has a very high level of proficiency in the operation of assistive computing devices, including the BrailleNote APEX notetaker. At the time of the study, she was a braille trainer for Deaf people and for those with Usher syndrome. She had never owned a smartphone but had been using a braille display notetaker on a daily basis since the early 2000 s.

\section{Materials}

Communication technology. The CAD used in the study was based on a braille display notetaker connected by Bluetooth to an iPhone (Figure 1). The software required, i.e. the iOS operating system, the VoiceOver screen reader and the HWCom application, all run on the iPhone. The VoiceOver application plays a central role in this architecture, as it allows for a Bluetooth connection between the iPhone and the braille display note taker.

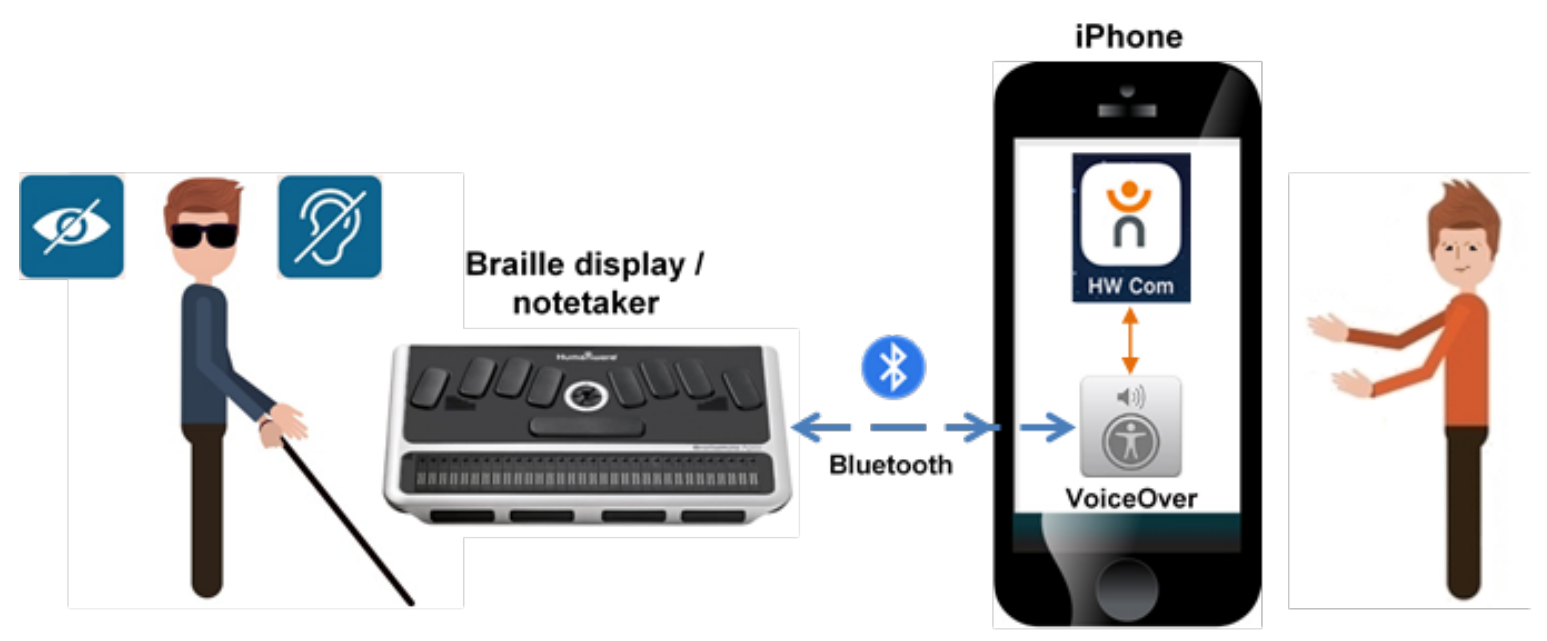

Figure 1. Architecture of the CAD 
The chat application allows interactions between the two types of users (without sensory impairment and with deafblindness). The individual with deafblindness uses two complementary devices: (1) the VoiceOver screen reader which, through a virtual cursor, allows the user to read content, activate options and trigger commands on the iPhone, and (2) the braille display notetaker, which displays the content read by VoiceOver and allows to move the cursor in the iPhone interface. The detailed architecture of the components used in this study was as follows: HumanWare communicator (or HWCom) is a software application developed in French by Technologies HumanWare Inc. (Drummondville, QC, Canada) in partnership with INLB. The application was compatible with the iOS 7 operating system. The application had invitation to dialogue and speech turn management functions, but also offered customizable functions. In preparation for this study, deafblindness experts compared the French version of this application to an application already on the market (HIMS Chat; HIMS Fingertip Communication, Daejeon, South Korea). A series of criteria was used, including functionalities, ease of learning and use, and size. The application developed in French was in every way equivalent to HIMS. BrailleNote Apex notetaker [Technologies HumanWare Inc., Drummondville, QC, Canada] consisted of a laptop with a braille display and a keyboard. Its flash memory allowed it to run basic desktop and communication applications. It was equipped with a Bluetooth transceiver device for connecting to nearby devices, such as a smartphone. The BrailleNote Apex notetaker is no longer available on the market. An Apple iPhone 5 (16 GB) [Apple Inc., Cupertino, CA, USA] equipped with iOS 7 operating system was employed. iOS ran the VoiceOver screen reader, whose role was to provide a voice output that was transposed into braille by the braille display notetaker. VoiceOver also provided a virtual cursor that a person with blindness can use to interact with most of the phone's features.

Data collection tools. The following tools were developed for the study. Due to specific requirements related to communicating with the participant, the two interview guides were developed with a concern for economy in terms of the number of questions and the simplicity of their wording. An interview guide about the perceived productivity of communication interaction, whose first function was to collect the user's subjective assessment of the CAD's productivity. It comprised five questions about effectiveness, efficiency and errors and drew inspiration from ISO 9241-11:2018 (International Organization for Standardization, 2010) and the ÉSAT questionnaire (Demers, Weiss-Lambrou, \& Ska, 2000). The answer options were: "Yes / Moderately / No". This interview guide also collected freely expressed comments (see Appendix A). An interview guide on the participant's emotional experience, which was intended to capture her emotional perceptions and reactions related to her use of the CAD under study. The guide was comprised of eight questions and drew from the Psychosocial Impact of Assistive Devices Scale (PIADS) questionnaire (Day \& Jutai, 1996) and the Post Study System Usability Questionnaire (PSSUQ) (Lewis, 1993). The answer options were: "Yes / Moderately / No". The guide was also used to gather freely expressed comments (see 
Appendix A). An observation grid for recording events in the field to document any unexpected events that occurred during the interactions, in order to contextualize the results, as required (see Appendix B). An observation grid on the functioning of the communication interaction, consisting of a subset of items in the PTECCA (Iché et al., 2012), in particular those affecting speech turns and feedback loops, organized in a structure proposed by Van Den Tillaart (2011): opening, maintaining and closing contact. The PTECCA answer options were replaced by a complete count of all communicative events in the grid (see Appendix C).

Recording equipment. Two devices were used to record the raw data. A Sony Handycam HDR-CX220 [Sony Corporation, Tokyo, Japan] video camera, to capture the participant's training on how to use the CAD, the activities in real-life settings (restaurant outings), and the interviews conducted with the participant through interpreters. A Panasonic Digital Voice Recorder RR-US570 [Panasonic, Mississauga, ON, Canada] for interviews with the attendant and the waitress.

\section{Data Collection and Analysis}

There were three types of contributors to data collection and analysis. Research professionals: Two CRIR-INLB research officers were involved in all the activities with the participant: the person mostly in charge of the methods and the person mostly in charge of the technology. Deafblindness professionals: A Vision Impairment Rehabilitation Specialist (VIRS) who conducted the training with the device and the follow-up session. The special educator who accompanied the participant during the outings participated in the analysis of the data on how the communication interaction functioned (Objective 3). A deafblindness counsellor from IRD with more than 40 years of experience with clients with deafblindness participated as an observer during all three phases and was consulted at various stages of the study. Interpreters: Three interpreters assisted the members of the study team in their communications with the participant. They were provided by the Service d'interprétation visuelle et tactile (visual and tactile interpretation service). Their task consisted mainly of interpreting the questions posed and answers given during the interviews.

\section{Procedure}

Before the study began, written informed consent of the participant, her attendant and the waitress who used the CAD in phase $C$ was obtained. Prior to the study, a Vision Impairment Rehabilitation Specialist from the joint INLB-IRD deafblindness program trained the participant on how to use the CAD in a single 2-hour session, and participated in a followup meeting with the participant after her first two weeks of device use. The purpose of this step was to ensure that the participant could use the CAD effectively before embarking on real-life situations. The follow-up was to verify that the CAD was being used correctly, to identify the participant's challenges and achievements with the device as well as to answer 
her questions. After this follow-up and before the beginning of the study, the participant benefited from a standalone use of the device for 10 weeks spread over 27 weeks since the device had to be withdrawn twice because of technical problems.

Figure 2 illustrates the procedure components used to collect the data and the items studied (the colored arrows) by activity (the rectangles). The participants in each activity are indicated in brackets.

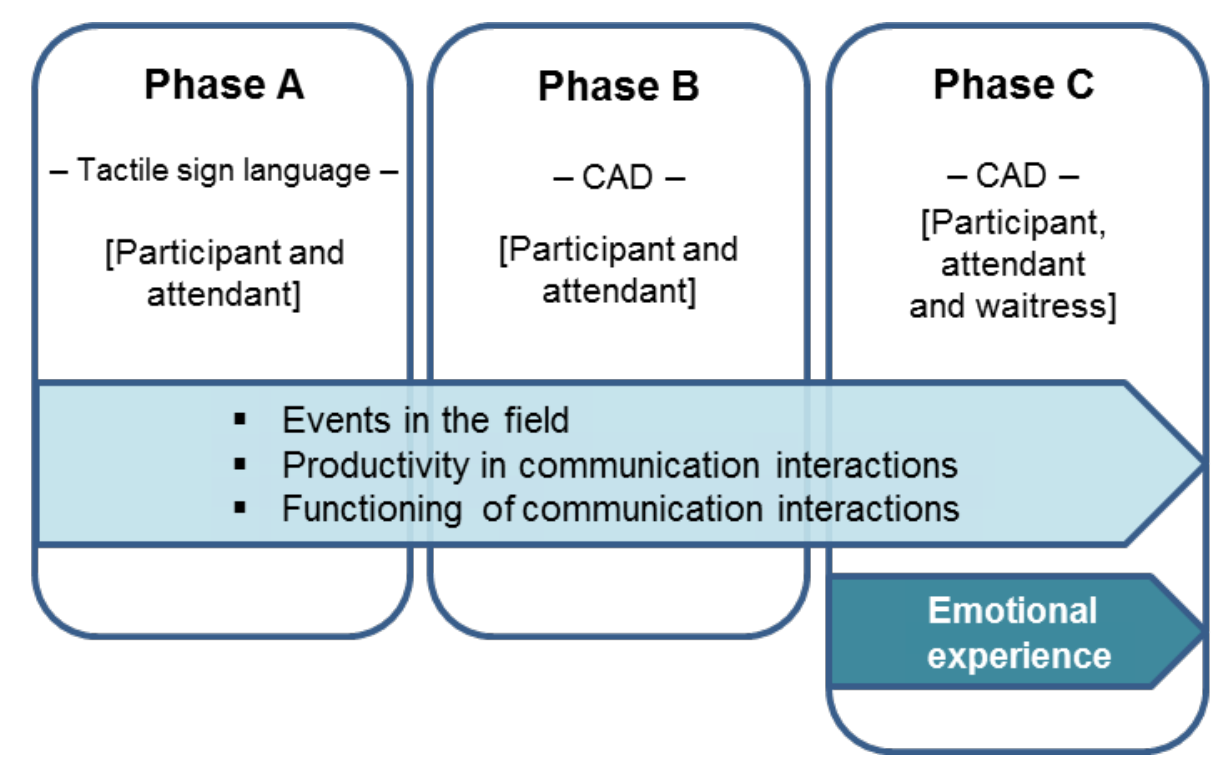

Figure 2. Participants and study items by activity

A sighted and hearing special-education teacher from the joint deafblindness program, whose mother tongue was LSQ (langue des signes québécoise / Quebec sign language), served as an attendant to the participant at all three restaurant outings. Prior to her participation in the study, she knew the CAD by reputation only. Her experience with texting or chat applications was rated "normal".

The waitress present at each phase was somewhat familiar with the participant as she was a regular customer at the restaurant. The waitress had regular experience with texting or chat applications. During phases A and B, she communicated with the participant through the attendant, who served as an interpreter. During phase $C$, she communicated directly with the participant using the CAD. For each phase, the participant and her attendant were instructed to have a meal and talk to each other on topics of their choice. In order to promote maximum interaction between the participant, the attendant and the waitress, the participant was encouraged to choose a dish with which she was unfamiliar. All three outings in real-life situations were captured using a video camera.

The participant and the attendant completed individual debriefing interviews following each of the restaurant outings. The purpose of the interviews was to assess perceived 
productivity in the communication interaction (phases A, B and C) and the participant's emotional experience with the device (phase $C$ ). The interviews were conducted at the participant's home less than two hours after the outing. Only one interview took place the next day and outside the participant's home (with the attendant). All interviews were audio (attendant and waitress) or video-recorded (person with DB). Following phase C, at which the waitress communicated directly with the participant using the CAD, the waitress completed a debriefing interview that took place less than two hours after the interaction at the restaurant.

During all three phases, a researcher observed the interactions on site, taking observation notes using the Field Events Observation Grid. As the use of the CAD was expected to increase the risk of loop breaks, special attention was given to this type of event (see Appendix B). Thus, any occurrence of a loop break called for a brief written description of the cause and resolution (if any) of the issue, as well as the step of the meal and the time it happened. With regard to the task of documenting other types of difficulties and observations collected with the grid, support was provided by a deafblindness counsellor who commented in real-time on specific events or interactions that, in his expert opinion, were worthwhile.

\section{Results}

\section{Objective 1. Evaluation of the Perceived Productivity}

In this study, the participant engaged in three real-life situations involving ordering, eating and paying for a meal at the restaurant (see Figure 2). In order to better understand the results on perceived productivity, it is useful to first report the unexpected events that occurred during the interactions. These events, recorded with the Field Events Observation Grid (Appendix B), were all issues related to communicating with the CAD. They have been classified in three categories. Table 1 shows their distribution by phase.

Table 1.

Events observed in the field

\begin{tabular}{|c|c|c|c|c|}
\hline \multirow[b]{2}{*}{ Type } & \multicolumn{4}{|c|}{ Frequencies } \\
\hline & Phase A & Phase B & Phase C & Total \\
\hline Software issue & NA & 3 & 2 & 5 \\
\hline Speech turns management issue & 0 & 3 & 0 & 3 \\
\hline Handling issue & NA & 0 & 1 & 1 \\
\hline Total & - & 6 & 3 & 9 \\
\hline
\end{tabular}

Note. NA = Not applicable. 
Software issues accounted for more than half of all the problems encountered. The second most frequent were speech turn management issues, which occurred solely during the first outing with the CAD (phase B). The alternation of speech turns imposed by HWCom made it impossible for a user to send two consecutive messages. The interlocutor who wanted to do this had to ask his interlocutor, by another means of communication, to actively give him his turn by "sending" an empty message. Only one handling problem was observed (phase C), which was due to the sensitivity of the iPhone screen.

Perceived productivity in the communication interaction was investigated over the three phases through five interview questions on the following issues: increase in the communication, speed of the communication, concentration required to communicate, occurrence of errors during the communication and severity of error consequences.

The answers to the questions and the comments were classified by the two research professionals in charge of the study through consensus. For each phase, and for each type of respondent, yes/no answers and positive and negative comments were counted. The "moderately" answers and neutral comments have been excluded in order to clearly characterize the answers collected. Redundant comments were counted as only one. Table 2 summarizes the results of the interviews. The variation in frequencies shown in the table is due to the exclusion of some answers and the unlimited number of comments that could be expressed by the respondents to each of the questions. The use of the percentages is an attempt to smooth out this variation.

The outing during which no technical aid was used (phase A) only garnered positive perceptions. Negative perceptions were expressed following the two outings with the CAD (phases B and C), and they centered mainly on the speed of communication and the occurrence of errors and their consequences. The participant was unhappy with having to wait for her interlocutor's message to be sent before she could read it, unlike her sighted interlocutor who could read the message to be received as it was being written. In addition, the participant had no technical means for knowing whether a message was currently being prepared for her. For the participant and her attendant, the proportion of positive perceptions increased between the two phases with the CAD. The waitress had very positive perceptions, while it was her first experience with a CAD. 
Table 2.

Summary of positive and negative perceptions per interlocutor regarding their perceived productivity of the communication interaction.

\begin{tabular}{|c|c|c|c|c|c|c|}
\hline & \multicolumn{2}{|c|}{$\begin{array}{c}\text { Phase A } \\
\text { without CAD }\end{array}$} & \multicolumn{2}{|c|}{$\begin{array}{c}\text { Phase B } \\
\text { with CAD }\end{array}$} & \multicolumn{2}{|c|}{$\begin{array}{c}\text { Phase C } \\
\text { with CAD }\end{array}$} \\
\hline & $\begin{array}{c}\text { Positive } \\
(\%)\end{array}$ & $\begin{array}{c}\text { Negative } \\
(\%)\end{array}$ & $\begin{array}{c}\text { Positive } \\
(\%)\end{array}$ & $\begin{array}{c}\text { Negative } \\
(\%)\end{array}$ & $\begin{array}{c}\text { Positive } \\
(\%)\end{array}$ & $\begin{array}{c}\text { Negative } \\
(\%)\end{array}$ \\
\hline Participant & $5(100 \%)$ & $0(0 \%)$ & $3(43 \%)$ & $4(57 \%)$ & $3(50 \%)$ & $3(50 \%)$ \\
\hline Attendant & 7 (100\%) & $0(0 \%)$ & $4(50 \%)$ & $4(50 \%)$ & $4(66 \%)$ & $2(33 \%)$ \\
\hline Waitress & - & - & - & - & $6(100 \%)$ & $0(\%)$ \\
\hline Total & $12(100 \%)$ & $0(0 \%)$ & $7(47 \%)$ & $8(53 \%)$ & $13(72 \%)$ & $5(28 \%)$ \\
\hline
\end{tabular}

\section{Objective 2. Evaluation of the Emotional Experience}

The interview questions used to characterize the participant's affective experience addressed the following: sense of competence, sense of confidence, sense of autonomy, frustration, fear of the iPhone being stolen, willingness to try new experiences, sense of having a better quality of life and pride in using an iPhone. The emotional experience interview was completed at the end of phase $C$. The data were compiled in a manner similar to that used for perceived productivity. All the answers to the questions were positive and, out of five comments collected, four were positive and only one was negative. The negative comment concerned the format of the braille display notetaker, which the participant would have preferred to be slightly more compact.

\section{Objective 3. Description of the Communication Interactions}

The interactions were studied by observing how the communication interaction worked. It relied on an examination of the video recordings, as structured by an observation grid. Each of the observations entered in the grid represent a consensus reached between the research officer in charge of the methodology and the special educator who accompanied the participant on the three outings. 
Table 3.

Compilation, per phase, of observations related to the functioning of the communication interaction

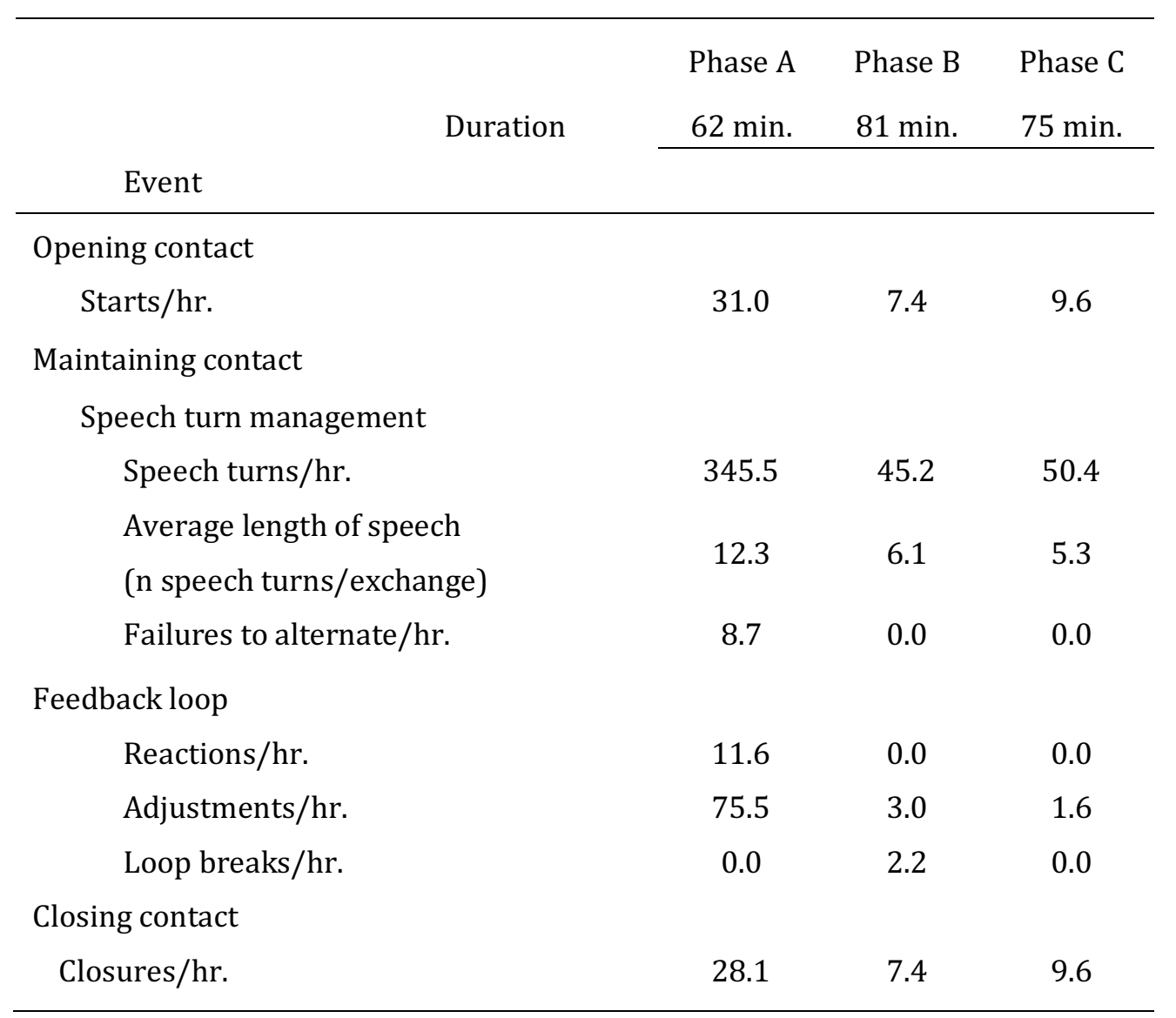

The grid provided the event frequency for each phase. Table 3 presents a compilation of the observations. Appendix A presents the definitions of the observed items.

The conversation using tactile sign language (phase A), when compared on an hourly basis (per hour) with the conversations with the CAD (phases B and C), generated a much higher frequency of events for all the items examined, with the exception of loop breaks. In particular, phase A produced 25 and 47 times more adjustments as well as 11.6 reactions per hour, compared to none for phases B and C.

Finally, there was no loop break in phase A. All the observed loop breaks occurred in phase $B$ and were directly related to use of the technology. 


\section{Discussion}

The purpose of the present case report was to gauge the value and effectiveness of a braille communication assistance device (CAD) for individuals with deafblindness.

\section{Objectives 1 and 2}

The CAD used in this study mostly provided positive attitudes and perceptions to both the participant and her interlocutors. Although there were some recurring technical problems that were critical to effective communication, and the CAD generated relatively poor communication compared to sign language, the participant's emotional experience was positive and sustained. She was also positive with regard to her perceived productivity, although she was somewhat critical about some targeted aspects of the CAD. Due to her mastery of tactile sign language and the fact that she had heard about technical problems with the CAD, the attendant admitted having anticipated losses in terms of communication fluidity and richness, that might impair perceived productivity. Even if the attendant expressed a reduction of perceived productivity with the use of the CAD compared to the use of tactile sign language, use of the CAD in a real-life situation limited her initially negative attitude, such that, even before the end of the study she became convinced of the value added by a CAD, regardless of the technical problems. The information collected from the waitress demonstrates that a naïve user's initial use of the CAD is positive, being marked by enthusiasm and satisfaction. With neither positive nor negative expectations, she was simply thrilled to be able to communicate effectively with a person with DB.

\section{Objective 3}

Although all aspects of the grid on the functioning of the communication interaction were part of an interaction model, a distinction needs to be made: events identified as reactions and adjustments are related to the content of conversations, while other events (speech turns, interaction initiation or closure, alternation) are completely independent of what is being said.

Reactions and adjustments were much more frequent in the tactile sign language conversation between the interlocutors than in the conversations going through the CAD. The colossal difference between the number of adjustments and reactions observed during phase A compared to phases $B$ and $C$ suggest that the constraints introduced by the use of a CAD (speech turns, waiting, and the unavailability of a message being prepared for the person with DB) changes the nature of the exchanges, mainly restricting them to activities aimed at obtaining results. 


\section{Recommendations for Better Communication Using a CAD}

Despite every respondent's satisfaction, the technology used did not seem entirely compatible with the communication task for which it was intended. Since most of the potential users of this technology (people with deafblindness) may not have the high-level expertise of the individual who participated in the study, some elements seemed minimally required to ensure efficient and comfortable communication using a CAD. Based on that premise, discussions of the results between the members of the study team and the deafblindness counsellor lead to four suggestions for improvements. These are related to 1) invitation and instructions, 2) notification of intent, 3) speech turns and 4) feedback to the person with deafblindness.

Invitation and instructions. It is essential for the CAD to offer the sighted person an explicit invitation to communicate, just as is the case with HWCom. This message is an integral part of the context of communication with a person with DB. It is intended to indicate to the potential interlocutor how to accept the person's invitation ("press OK") when s/he is presented with the iPhone for initiating a conversation. Using the iPhone's ringing/vibrating function to attract the interlocutor's attention, as the function is employed by the HWCom, is also desirable. Under certain circumstances, it may be helpful to use a card to draw someone's attention before presenting the iPhone.

Notification of intent. There are strategies for resuming a momentarily suspended conversation that are both valuable to attract the deafblind person's attention and important for the quality of communication and the interlocutors' comfort. For example, consider a waitress, who must signify her presence to a person with DB when returning to the table. To inform the person with DB of her interest in continuing or initiating an exchange, she can opt for one of the two usual strategies: producing vibrations by banging on the table or touching the person's hand. It would be useful to have an instruction integrated into the welcome message of an improved CAD that would suggest such strategies to an interlocutor initiating a conversation with a person with DB.

Speech turns. It emerged that a speech management function that is too rigid, such as that used by HWCom, poses problems when an interlocutor wishes to send two consecutive messages. On the other hand, unmanaged speech turns can theoretically lead to confusion and a mishandling of the CAD. A middle-of-the-road solution that works like text messaging would be ideal. It would display the interlocutors' messages separately but would give the opportunity to communicate at any time. In order to facilitate the exchange, the instruction accompanying the conversation opening could even inform the interlocutor of some written conventions related to speech turn management for deaf people, such as GA for Go Ahead and SK for Stop Keying.

Feedback to the person with DB. The participant repeatedly expressed her frustration with having to wait for her interlocutor's message. An improved CAD should allow real-time 
reading of messages intended for the person with DB. If this proves impossible, the application should at least transmit a generic message to the person with $\mathrm{DB}$, informing her that her interlocutor is writing, as Messenger does on the Internet.

\section{Limitations}

A single case study limits comparisons and rules out generalizations. The participant's outstanding information technology competency profile highlights the uniqueness of this study and the results obtained. Training persons with DB with weaker computer skills on the use of the CAD would be necessary in order to improve, refine and adapt the training content and format.

The data were obtained solely from goal-oriented real-life situations (having a meal in a restaurant). As appraisals from interlocutors whose communication objective would be emotional (maintaining links) rather than goal-oriented (performing a task to obtain a result) have not be collected, hints about the utilitarian aspect of the CAD as opposed to its ability to nurture emotional bonds are missing. More research on this aspect seems highly desirable, as establishing and maintaining bonds with relatives constitute basic and natural functions of communication.

Nonetheless, this exploratory study made it possible to assess the value of this type of technology for persons with DB and propose improvements to this particular CAD. Given these results, the next step is to carry out a study with a device that would take into account the limitations noted and recommendations made here.

\section{Conclusion}

This case study has demonstrated the relevance, usefulness and interest of a communication support technology for a person with DB, not to mention the enthusiasm it generated with the interlocutor who was not familiar with tactile sign language. In addition to finding a solution to the technical failures encountered, the few improvements we have proposed seem essential. Any development of this communication support technology intended for users who have little experience with computers and electronic devices should be encouraged. However, we predict that, as future generations will be more computer literate in general, access to internet via their CAD's smartphone appears to be the next step. 


\section{References}

Dammeyer, J. (2014). Deafblindness: A review of the literature. Scandinavian Journal of Public Health, 42(7), 554-562. doi: 10.1177/1403494814544399

Dammeyer, J. (2015). Deafblindness and dual sensory loss research: Current status and future directions. World Journal of Otorhinolaryngology, 5(2), 37-40. doi: 10.5319/wjo.v5.i2.37

Day, H., \& Jutai, J. (1996). The Psychosocial Impact of Assistive Devices Scale (PIADS). A tool for evaluating the psychological benefits of rehabilitation technologies [manual, version 4.2b]. Toronto, ON: Authors.

Demers, L., Weiss-Lambrou, R., \& Ska, B. (2000). Outil d'Évaluation de la Satisfaction envers une Aide Technique (ÉSAT). Montréal, QC: Institut universitaire de gériatrie de Montréal ; Université de Montréal.

Hassenzahl, M. (2004). The thing and I: Understanding the relationship between user and product. In M. A. Blythe, K. Overbeeke, A. F. Monk \& P. C. Wright (Eds.), Funology: From usability to enjoyment (pp. 31-42). Dordrecht, Netherlands: Kluwer Academic Publishers.

Heine, C., \& Browning, C. (2015). Dual sensory loss in older adults: A systematic review. The Gerontologist, 55(5), 913-928. doi: 10.1093/geront/gnv074

Iché, A., Rives, C., \& Joyeux, N. (2012). Un bilan orthophonique d'approche écosystémique de la problématique aphasique : le PTECCA. [An ecosystemic approach of the orthophonic assessment of the aphasic problem]. Entretiens de Bichat (Orthophonie). Troubles expressifs: pathologies et remédiation, 81-94.

International Organization for Standardization. (2010). Ergonomics of human-system interaction. Part 210 : Human-centred design for interactive systems, ISO 9241-210:2010. Geneva, Switzerland: International Organization for Standardization.

International Organization for Standardization. (2016). Assistive products for persons with disability: Classification and terminology ISO 9999:2016(e) (6th ed.). Geneva, Switzerland: International Organization for Standardization.

International Organization for Standardization. (2018). Ergonomics of human-system interaction. Part 11: Usability: Definitions and concepts, ISO 9241-11:2018. Geneva, Switzerland: International Organization for Standardization.

Kerbrat-Orecchioni, C. (1986). « Nouvelle communication » et « analyse conversationnelle ». ["New communication" and "conversational analysis"]. Langue française. Communication et enseignement(70), 7-25. doi: 10.3406/lfr.1986.6368

LeJeune, B. J. (2010). Aging with dual sensory loss: Thoughts from consumer focus groups. AER Journal: Research and Practice in Visual Impairment and Blindness, 3(4), 146-152.

Lewis, J. R. (1993). IBM computer usability satisfaction questionnaires: Psychometric evaluation and instructions for use (Technical report 54.786). Boca Raton, FL: IBM Corporation. 
McDonnall, M. C., Crudden, A., LeJeune, B. J., Steverson, A., \& O'Donnell, N. (2016). Needs and challenges of seniors with combined hearing and vision loss. Journal of Visual Impairment \& Blindness, 110(6), 399-411.

Mordini, E., Nierling, L., Wolbring, G., Maia, M. J., Bratan, T., Capari, L., . . Kukk, P. (2018). Assistive technologies for people with disabilities. Part II: Current and emerging technologies. Brussels, Belgium: European Parliament.

Nordic Centre for Welfare and Social Issues. (2016). Nordic definition of deafblindness Retrieved from https://nordicwelfare.org/wp-content/uploads/2018/03/nordicdefinition-of-deafblindness.pdf

Ohtsuka, S., Hasegawa, S., Sasaki, N., \& Harakawa, T. (2012). Helen Keller Phone: A communication system for deaf-blind people using Body-Braille and Skype. Paper presented at the IEEE Consumer Communications and Networking Conference (CCNC), Las Vegas, NV, USA.

Ozioko, O., Taube, W., Hersh, M., \& Dahiya, R. (2017). SmartFingerBraille: A tactile sensing and actuation based communication glove for deafblind people. Paper presented at the IEEE 26th International Symposium on Industrial Electronics (ISIE), Edinburgh, United Kingdom.

Perfect, E., Jaiswal, A., \& Davies, T. C. (2018). Systematic review: Investigating the effectiveness of assistive technology to enable internet access for individuals with deafblindness. Assistive Technology, 1-10. doi: 10.1080/10400435.2018.1445136

Prain, M., McVilly, K., Ramcharan, P., Currie, S., \& Reece, J. (2010). Observing the behaviour and interactions of adults with congenital deafblindness living in community residences. Journal of Intellectual \& Developmental Disability, 35(2), 82-91. doi: $10.3109 / 13668251003716417$

Saunders, G. H., \& Echt, K. V. (2007). An overview of dual sensory impairment in older adults: Perspectives for rehabilitation. Trends in Amplification, 11(4), 243-258.

Schneider, J. M., Gopinath, B., McMahon, C. M., Leeder, S. R., Mitchell, P., \& Wang, J. J. (2011). Dual sensory impairment in older sge. Journal of Aging and Health, 23(8), 1309-1324. doi: 10.1177/0898264311408418

Van Den Tillaart, B. (2011). Landscape of Touch -Tactile Reciprocal Interaction. Paper presented at the XV Deafblind International World Conference: Inclusion for a lifetime of opportunities, Sao Paulo, Brazil.

Wittich, W., Jarry, J., Groulx, G., Southall, K., \& Gagne, J.-P. (2016). Rehabilitation and research priorities in deafblindness for the next decade. Journal of Visual Impairment \& Blindness, 110(4), 219-231.

Wittich, W., Southall, K., \& Johnson, A. P. (2016). Usability of assistive listening devices by older adults with low vision. Disability and Rehabilitation: Assistive Technology, 11(7), 564571. doi: 10.3109/17483107.2015.1042076 
Sylvie Cantin, M. A., Planning, Programming and Research Agent, CRIR Institut Nazareth et Louis-Braille of the CISSS de la Montérégie-Centre, Longueuil, QC, Canada; e-mail: <sylvie.cantin.inlb@ssss.gouv.qc.ca>. Walter de Abreu Cybis, D., Planning, Programming and Research Agent, CRIR - Institut Nazareth et Louis-Braille of the CISSS de la Montérégie-Centre, Longueuil, QC, Canada; e-mail: <walter.cybis.inlb@ssss.gouv.qc.ca>. SuzanneTrudeau, T.E.S. Special-Education Teacher, Institut Raymond-Dewar,CIUSSS du Centre-Sud-del'Ile-de-Montréal,Montreal, $\quad Q C, \quad$ Canada; $\quad$-mail: <suzanne.trudeau.ccsmtl@ssss.gouv.qc.ca>. Frédérique Poncet, OT, Ph. D., CRIR - Institut Nazareth et Louis-Braille of the CISSS de la Montérégie-Centre, Longueuil, QC, Canada; e-mail: <frederique.poncet.inlb@ssss.gouv.qc.ca>. Walter Wittich, PhD FAAO CLVT, Assistant Professor, School of Optometry, Université de Montréal, Montreal, Quebec, Canada; e-mail: <walter.wittich@umontreal.ca>.Marie-Chantal Wanet-Defalque,Ph. D., Associate Professor (retired), School of Optometry, Université de Montréal, Montreal, Quebec, Canada; e-mail: <machawand@gmail.com>. 


\section{Appendix A \\ Interview guides}

\section{Guide about perceived productivity of communication interaction}

Answer options: Yes / Moderately / No

Q1. Over time, do you think this device could cause you to communicate more?

Q2. Over time, do you think you could communicate faster using this device?

Q3. Over time, do you think you would need less concentration to communicate using the device?

Q4. Do you find that errors are often made with this device?

Q5. When mistakes are made, do you think they have serious consequences for communication?

\section{Guide on emotional experience}

Answer options: Yes / Moderately / No

Q1. Overall, has the use of the device given you a sense of competence?

Q2. Overall, did the use of the device give you confidence?

Q3. Overall, has the use of the device given you a greater sense of autonomy in your daily activities?

Q4. Overall, has the use of the device caused you frustration?

Q5. If you used this device every day, would you be afraid to get it stolen?

Q6. Overall, does the use of the device inspire you to try new experiences?

Q7. Do you think regular use of this device could improve your quality of life?

Q8. Overall, do you feel proud to use a system that includes an iPhone? 


\section{Appendix B}

\section{Field Events Observation Grid}

\begin{tabular}{|c|c|c|c|c|c|c|}
\hline Subject & Description & 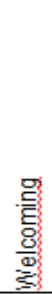 & 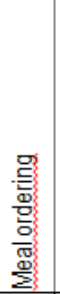 & 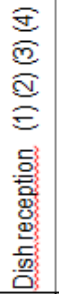 & 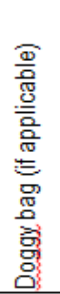 & Comments \\
\hline \multirow{5}{*}{$\begin{array}{l}\text { Communication } \\
\text { loop break }\end{array}$} & 1. & & & & & \\
\hline & 2. & & & & & \\
\hline & 3. & & & & & \\
\hline & 4. & & & & & \\
\hline & $\ldots$ & & & & & \\
\hline \multirow{5}{*}{$\begin{array}{l}\text { Other } \\
\text { difficulties }\end{array}$} & 1. & & & & & \\
\hline & 2. & & & & & \\
\hline & 3. & & & & & \\
\hline & 4. & & & & & \\
\hline & $\ldots$ & & & & & \\
\hline \multirow[t]{4}{*}{$\begin{array}{l}\text { Other } \\
\text { observations }\end{array}$} & 1. & & & & & \\
\hline & 2. & & & & & \\
\hline & 3. & & & & & \\
\hline & $\ldots$ & & & & & \\
\hline
\end{tabular}


Appendix C

Communication Interaction Function Observation Grid and definitions

\begin{tabular}{|c|c|c|c|c|c|c|c|c|c|c|c|c|c|c|c|c|c|c|c|c|c|c|c|c|}
\hline \multicolumn{19}{|c|}{ Positive events } & \multicolumn{4}{|c|}{ Negative events } & \multirow{3}{*}{ Timing } & \multirow{3}{*}{ Comments } \\
\hline \multicolumn{3}{|c|}{ Speech turn } & \multicolumn{3}{|c|}{$\begin{array}{l}\text { Interaction } \\
\text { initiation }\end{array}$} & \multicolumn{3}{|c|}{ Reaction } & \multicolumn{3}{|c|}{ Adjustment } & \multicolumn{4}{|c|}{ Explicit closure } & \multicolumn{3}{|c|}{ Implicit closure } & \multicolumn{3}{|c|}{$\begin{array}{l}\text { Failure to } \\
\text { alternate }\end{array}$} & \multirow[t]{2}{*}{$\begin{array}{l}\text { Loop } \\
\text { break }\end{array}$} & & \\
\hline Part. & Att. & Wait. & Part. & Att. & Wait & Part. & Att. & Wait & Part & At & W & & Part. & Att. & Wait. & Part. & Att. & Wait. & Part. & Att. & Wait. & & & \\
\hline & & & & & & & & & & & & & & & & & & & & & & & & \\
\hline & & & & & & & & & & & & & & & & & & & & & & & & \\
\hline & & & & & & & & & & & & & & & & & & & & & & & & \\
\hline & & & & & & & & & & & & & & & & & & & & & & & & \\
\hline & & & & & & & & & & & & & & & & & & & & & & & & \\
\hline & & & & & & & & & & & & & & & & & & & & & & & & \\
\hline & & & & & & & & & & & & & & & & & & & & & & & & \\
\hline & & & & & & & & & & & & & & & & & & & & & & & & \\
\hline & & & & & & & & & & & & & & & & & & & & & & & & \\
\hline & & & & & & & & & & & & & & & & & & & & & & & & \\
\hline & & & & & & & & & & & & & & & & & & & & & & & & \\
\hline & & & & & & & & & & & & & & & & & & & & & & & & \\
\hline & & & & & & & & & & & & & & & & & & & & & & & & \\
\hline & & & & & & & & & & & & & & & & & & & & & & & & \\
\hline & & & & & & & & & & & & & & & & & & & & & & & & \\
\hline & & & & & & & & & & & & & & & & & & & & & & & & \\
\hline & & & & & & & & & & & & & & & & & & & & & & & & \\
\hline & & & & & & & & & & & & & & & & & & & & & & & & \\
\hline & & & & & & & & & & & & & & & & & & & & & & & & \\
\hline & & & & & & & & & & & & & & & & & & & & & & & & \\
\hline & & & & & & & & & & & & & & & & & & & & & & & & \\
\hline & & & & & & & & & & & & & & & & & & & & & & & & \\
\hline
\end{tabular}




\section{Definitions}

\section{A. Opening contact}

a) Interaction initiation: a speech turn that represents a new initiative (in particular, by closing contact).

\section{B. Maintaining contact}

1. Speech turn management

a) Speech turn: when an individual takes a turn at speaking in a given feedback loop.

b) Alternation: full respect of the other interlocutor's speech turn. The table reports occurrences of failures to alternate, which is when someone interrupts the other interlocutor's speech turn to take a turn at speaking.

2. Feedback loop function

a) Reaction: expression of an emotion, an opinion or an idea, or taking action in response to what the other interlocutor is saying.

b) Adjustment: demonstrating attention and understanding or lack of understanding, reformulating, illustrating through examples, providing justifications or explanations, correcting a blunder, or validating one's understanding with the interlocutor.

c) Breaking the loop: reorganizing the communication in response to an external event that has just interrupted the feedback loop.

\section{Closing contact}

Closing the interaction: end of an exchange, whether it has been clearly announced or tacitly accepted by both interlocutors. There may be more interaction closures than there are initiations, such as when one interlocutor cuts off the other (producing two initiations for one closure). 